Article

\title{
Eco-Emission Analysis of Multi-Carrier Microgrid Integrated with Compressed Air and Power-to-Gas Energy Storage Technologies
}

\author{
Khashayar Hamedi ${ }^{1}$, Shahrbanoo Sadeghi ${ }^{2}$, Saeed Esfandi ${ }^{3} \mathbb{D}$, Mahdi Azimian ${ }^{4}$ and Hessam Golmohamadi ${ }^{5, *}$ (ID \\ 1 Department of Architectural Engineering, Ayatollah Amoli Branch, Islamic Azad University, \\ Amol 46151-43358, Iran; Khashayar.academic@gmail.com \\ 2 Department of Health, Safety, and Environment, School of Public Health and Safety, Shahid Beheshti \\ University of Medical Sciences, Tehran 19839-63113, Iran; Sadeghi-hse@sbmu.ac.ir \\ 3 School of Urban Planning, College of Fine Arts, University of Tehran, Tehran 14174-66191, Iran; \\ Esfandi_saeed@ut.ac.ir \\ 4 Department of Electrical and Computer Engineering, Kashan Branch, Islamic Azad University, \\ Kashan 87159-98151, Iran; m.azimian@iaukashan.ac.ir \\ 5 Department of Computer Science, Aalborg University, 9220 Aalborg, Denmark \\ * Correspondence: hessamgolmoh@cs.aau.dk
}

check for updates

Citation: Hamedi, K.; Sadeghi, S.; Esfandi, S.; Azimian, M.; Golmohamadi, H. Eco-Emission Analysis of Multi-Carrier Microgrid Integrated with Compressed Air and Power-to-Gas Energy Storage Technologies. Sustainability 2021, 13, 4681. https://doi.org/10.3390/ su13094681

Academic Editor: Ayman Attya

Received: 22 March 2021

Accepted: 9 April 2021

Published: 22 April 2021

Publisher's Note: MDPI stays neutral with regard to jurisdictional claims in published maps and institutional affiliations.

Copyright: (c) 2021 by the authors. Licensee MDPI, Basel, Switzerland. This article is an open access article distributed under the terms and conditions of the Creative Commons Attribution (CC BY) license (https:// creativecommons.org/licenses/by/ $4.0 /)$.

\begin{abstract}
Growing concerns about global greenhouse gas emissions have led power systems to utilize clean and highly efficient resources. In the meantime, renewable energy plays a vital role in energy prospects worldwide. However, the random nature of these resources has increased the demand for energy storage systems. On the other hand, due to the higher efficiency of multi-energy systems compared to single-energy systems, the development of such systems, which are based on different types of energy carriers, will be more attractive for the utilities. Thus, this paper represents a multi-objective assessment for the operation of a multi-carrier microgrid (MCMG) in the presence of high-efficiency technologies comprising compressed air energy storage (CAES) and power-to-gas (P2G) systems. The objective of the model is to minimize the operation cost and environmental pollution. CAES has a simple-cycle mode operation besides the charging and discharging modes to provide more flexibility in the system. Furthermore, the demand response program is employed in the model to mitigate the peaks. The proposed system participates in both electricity and gas markets to supply the energy requirements. The weighted sum approach and fuzzy-based decision-making are employed to compromise the optimum solutions for conflicting objective functions. The multiobjective model is examined on a sample system, and the results for different cases are discussed. The results show that coupling CAES and P2G systems mitigate the wind power curtailment and minimize the cost and pollution up to $14.2 \%$ and $9.6 \%$, respectively.
\end{abstract}

Keywords: compressed air energy storage; demand response; emission; multi-carrier microgrid; multi-objective programming; power-to-gas facility

\section{Introduction}

\subsection{Literature Review}

Nowadays, the eminence of alternative eco-friendly resources in lieu of traditional resources is highlighted to overcome the energy and climate change crises [1]. The International Energy Agency estimates a $130 \%$ rise in $\mathrm{CO}_{2}$ emissions, a $70 \%$ rise in oil consumption, and a $6{ }^{\circ} \mathrm{C}$ rise in the global average temperature by 2050 [2]. The penetration of renewable energy sources (RES) would replace carbon-intensive energy resources and decrease global warming emissions [3]. Microgrids (MGs) as a viable solution against the concerns above have been receiving increasing attention to facilitate the large-scale penetration of distributed energy resources, particularly RESs [4]. Thus, RESs such as wind farms have received immense attention in the literature during the last decades. According to the 
International Energy Agency's statistics reported in [5], the share of annual wind power generation of 2182 TWh is estimated by 2030.

Although developing RESs have various advantages, their volatility and uncertainties due to their probabilistic nature pose intense challenges to the power system's economic operation and management. One effective way to cope with the volatilities of RES is employing energy storage systems to compensate for the RESs fluctuation. Some cases of this specific technology are battery storage systems [6], hydrogen storage systems [7], battery storage [8], compressed air energy storage (CAES), and power to the gas facility (P2G). The CAES system is one of the large-scale storage systems that can pressurize the air into the salt caves or underground reservoirs with a compressor during charging mode and release the compressed air into the turbine to generate power during discharging mode [9]. Although there are only two large-scale practical CAES plants in operation at present $[10,11]$, various studies demonstrate the positive advantage of CAES in recent years, which is used as a standalone option or mixed with other energy sources. For example, a revision of the latest studies on the CAES system to enhance CAES's fundamental understanding was investigated [12]. In [13], a self-scheduling method considering CAES thermodynamic characteristics for participating in energy markets was presented to maximize the system profit. In [14], an integrated photovoltaic-CAES system was investigated to show the effectiveness of applying CAES in exploiting the photovoltaic energy system's surplus energy. In [15], a two-stage bi-level approach for a generation company owning CAES, thermal generators, and wind units was investigated to improve its profitability. An economically stochastic security-constrained unit commitment model considering CAES and wind power generation was developed [16]. The proposed scheduling model can manage the uncertainty of wind output and reduce the expected operational cost. The economic energy scheduling of a site comprising various units, e.g., CAES, thermal generators, and wind power plant, is conducted using the look-ahead approach [17]. The demand response program (DRP) is employed in the model to minimize the total cost. An integrated wind-photovoltaic system incorporated with CAES, DRP, and thermal units aiming to the cost minimization was studied in [18]. A scenario-based bi-level approach for designing a hybrid system pinpointed by wind, CAES, and thermal units in addition to DRP was proposed in [19]. The first objective minimizes total daily operational costs, while the second objective minimizes the total emission cost. An information gap decision theory (IGDT)-based risk constraint bidding strategy for a CAES-self scheduling model was studied to maximize the profit by participating in the power market [20]. The results illustrate profitable scheduling in the presence of CAES considering the price uncertainty. Stochastic energy management of the intelligent electric vehicle and DRP was proposed by [21].

P2G facility as an innovative technology that effectively converts the surplus electrical energy into other energy vectors can improve system flexibility [22]. This promising technology not only plays a significant role in storing energy but also is known as an environmental-friendly technology [23]. The P2G allows the power system to have a bidirectional coupling with other energy systems such as natural gas and heating district by trading synthetic natural gas and the produced heat as the final power conversion product [24]. Many researchers have used the P2G facility to improve the integrated power and natural gas systems' reliability and security. The environmental performance of P2G using life cycle assessment was investigated [25] to analyze the effects of the approach for $\mathrm{CO}_{2}$ capturing, processes of producing hydrogen and methane, and environmental impacts of the P2G facility. The coordinated renewable Energy and P2G was considered a potential solution to diminish $\mathrm{CO}_{2}$ emission and improve wind power variability in the power grid [26]. An optimal scheduling method of combined P2G and gas-fired power plant systems to quantify the coordinated system ability for reducing $\mathrm{CO}_{2}$ emission and employing renewable resources was investigated in [27]. In [28], the operation of a collocated gas-fired unit, P2G facility, and natural gas storage system was analyzed via a robust day-ahead scheduling model to minimize the total operation cost of electricity and 
gas supply. Also, the coupled energy system in the presence of P2G facilities operating in an uncertain environment was investigated in [29]. The proposed two-stage robust optimization method can effectively improve the system's flexibility to decrease system operational cost. A management strategy considering a multi-objective optimization framework for a multi-carrier MG (MCMG) system consists of integrated local wind resources, P2G facility, and solid oxide fuel cell/gas hybrid turbine system was proposed in [30]. An optimal multi-objective optimization framework using Conditional Value at Risk criteria and a robust optimization approach was presented in [31]. Profit maximization and risk minimization aims are ensued in the model by coordinating virtual power plant and P2G facility. In [32], the multi-objective day-ahead scheduling method was used to analyze the effect of the P2G in a coupled energy system comprising electricity, gas, and district heating systems. The renewable energy integration in combined cooling, heating, and power processes was developed [33]. The distributed coordination control for multiMGs based on the game-theoretic non-cooperative method was studied in [34]. In [35], the need for intelligent energy networks for a higher global efficiency through a multi-carrier system was developed.

Similarly, a multi-objective two-stage structure for both electricity and gas networks regarding P2G facility, DRP, and wind energy was investigated [36]. An economic emission analysis considering uncertainties associated with energy demand, gas demand, and wind power output was conducted to maximize the total profit and minimize $\mathrm{CO}_{2}$ gas emission in a multi-objective model. In [37], the optimal operation of a hybrid MG based on heating, cooling, and power in the presence of CAES and refrigeration based on a multi-objective framework was studied. Similarly, a hybrid system comprising various units such as photovoltaic, CAES, gas-fired integrated with combined heat and power technology was studied to analyze the CAES system's performance in a multi-objective framework [38]. In [39], optimization of power-to-heat flexibility for buildings considering the day-ahead market was studied.

A multi-objective unit commitment problem using a two-stage stochastic programming method was employed in [40]. The model aims to minimize the operation cost and emission pollution associated with an integrated smart grid consists electric vehicles, CAES system, RESs, and DRP. The energy management of a renewable-based islanded MG integrated with DRP and pumped-storage was studied to balance demand and generation sides [41]. The optimal scheduling of a district coupled power-gas system with wind energy considering demand flexibility and CAES was studied [42]. The robust and opportunistic approaches are implemented in the model. In [43], techno-economic analysis of a RES-based islanded MG considering DRP and energy storage was investigated. A novel two-stage optimization method based on the combination of genetic algorithm and dynamic programming was proposed to attain the optimal scheduling sets of a coupled energy systems leveraging DRP and energy storage [44]. In [45,46], various combinations of energy storage technology and DRP were analyzed to decrease wind curtailment. The probabilistic performance of the ice storage system on the energy hub operation penetrated with wind turbine leveraging DRP was represented [47]. The optimal scheduling problem of an energy hub structure equipped with combined heat and power, boiler, power-to-gas storage, thermal energy storage, and electrical energy storage was presented. The paper in [48] investigated the role of power-to-gas technology in decreasing the operation cost of the energy hub's operator while providing electrical, thermal, and gas demands. In [49], a two-stage robust approach was developed for coupled combined heat and power systems and P2G MGs under wind power uncertainty.

\subsection{Contribution and Novelty}

Although several studies have reported on the CAES system considering economic issues, few studies have analyzed the CAES system in coordination with P2G facilities integrated with electricity and natural gas infrastructures from economic and environmental perspectives $[25,28,41,46]$. To the best of the authors' knowledge, the economic, technical, 
and environmental advantages of the coupled CAES-P2G-wind turbine-based system leveraging DRP have not been investigated in prior works. Thus, the economic-environmental dispatch strategy for a hybrid MCMG system based on a multi-objective optimization framework is analyzed in this work. The coordinated scheduling of the MCMG system, including wind plant, CAES, and P2G facilities, can play a vital role in satisfying the power system's energy requirements in an eco-friendly manner. Table 1 summarizes the taxonomy of reviewed papers in operation studies of hybrid multi-energy systems. The differences between the operation problem of this work and previous works are specified.

Table 1. Comparing different studies with present work.

\begin{tabular}{|c|c|c|c|c|c|c|c|c|c|c|}
\hline \multirow{2}{*}{ Refs } & \multirow{2}{*}{$\begin{array}{c}\text { Multi-Energy } \\
\text { System Scheduling }\end{array}$} & \multirow{2}{*}{ CAES $^{1}$} & \multirow{2}{*}{$\mathrm{P}^{2} \mathrm{G}^{2}$} & \multirow{2}{*}{$\mathrm{DRP}^{3}$} & \multicolumn{2}{|c|}{ Objective } & \multicolumn{3}{|c|}{ Uncertainty } & \multirow{2}{*}{ Model } \\
\hline & & & & & Economic & Emission & Wind & Price & Load & \\
\hline [13] & $x$ & $\sqrt{ }$ & $x$ & $x$ & $\sqrt{ }$ & $x$ & $x$ & $\sqrt{ }$ & $\sqrt{ }$ & Stochastic \\
\hline [19] & $x$ & $\sqrt{ }$ & $x$ & $\sqrt{ }$ & $\sqrt{ }$ & $\sqrt{ }$ & $x$ & $\sqrt{ }$ & $\sqrt{ }$ & Stochastic \\
\hline [20] & $\times$ & $\sqrt{ }$ & $\times$ & $\sqrt{ }$ & $\times$ & $\sqrt{ }$ & $x$ & $\sqrt{ }$ & $\sqrt{ }$ & IGDT $^{4}$ \\
\hline [27] & $x$ & $\times$ & $\sqrt{ }$ & $\times$ & $\sqrt{ }$ & $\sqrt{ }$ & $x$ & $\times$ & $\times$ & Deterministic \\
\hline [36] & $\sqrt{ }$ & $\times$ & $\sqrt{ }$ & $\sqrt{ }$ & $\sqrt{ }$ & $\sqrt{ }$ & $\sqrt{ }$ & $x$ & $\sqrt{ }$ & Stochastic \\
\hline [38] & $\sqrt{ }$ & $\sqrt{ }$ & $x$ & $\sqrt{ }$ & $\sqrt{ }$ & $\sqrt{ }$ & $\sqrt{ }$ & $x$ & $\sqrt{ }$ & Stochastic \\
\hline This work & $\sqrt{ }$ & $\sqrt{ }$ & $\sqrt{ }$ & $\sqrt{ }$ & $\sqrt{ }$ & $\sqrt{ }$ & $\sqrt{ }$ & $\sqrt{ }$ & $\sqrt{ }$ & Stochastic \\
\hline
\end{tabular}

${ }^{1}$ CAES: compressed air energy storage, ${ }^{2}$ P2G: power-to-gas, ${ }^{3}$ DRP: demand response program, ${ }^{4}$ IGDT: information gap decision theory.

According to the above description, this work focuses on the optimal eco-emission assessment of coordinated CAES, P2G, DRP, and wind farm hybrid MCMG systems participating in the day-ahead market. The proposed coordinated operation approach aims to find the Pareto-optimal set by minimizing the total operation cost and pollution as well as facilitating more integration of RESs into the hybrid MCMG system enabled with P2G and CAES systems. The proposed system serves both electrical and gas loads. Wind energy, load demand, and power price are considered random parameters and modeled via stochastic programming. Besides, the weighted sum fuzzy-based decision making is employed to solve the proposed multi-objective model. Briefly, the main novelty of this research is highlighted as:

- Proposing a hybrid MCMG system consists of CAES, P2G, and wind farms, contributing to environmental and economic benefits.

- Investigating the coordinated operation of coupled CAES-P2G to facilitate more integration of wind energy resources into the power system.

- Proposing multi-objective scenario-based stochastic programming to the eco-emission analysis of the proposed MCMG and extending the weighted sum fuzzy-based decision-making to solve the model.

- Employing the shiftable strategy of DRP in the hybrid system as a flexible source to mitigate the load curve under probable behavior of wind power, load demand, and power market price.

\subsection{Paper Organization}

The rest of this work is organized as follows. In Section 2, a brief review of the P2G concept and the problem description is provided. The problem formulation for the economic and environmental goals is represented in Section 3. The methodology of the proposed multi-objective model based on the weighted sum approach is described in Section 4. Numerical results of different cases are represented in Section 5. Section 6 concludes the paper.

\section{The Proposed Framework}

\subsection{P2G Concept}

It can be seen from previous studies that the options for providing large-scale seasonal or long-term storage are limited to several storage systems such as P2G technology with flexible storage durations from minutes to months [50]. P2G is a promising technology that 
is divided into two processes. The first type of P2G process converts the excess electricity into hydrogen and oxygen through water electrolysis. The produced hydrogen can be utilized in other applications that require hy $2 \mathrm{H}_{2} \mathrm{O} \rightarrow 2 \mathrm{H}_{2}+\mathrm{O}_{2}$ drogen as feedstock or fuel or be interacted with $\mathrm{CO}_{2}$ through Sabatier reaction to produce synthetic natural gas $[51,52]$. The specific chemical reactions are described by:

$$
\begin{gathered}
2 \mathrm{H}_{2} \mathrm{O} \rightarrow 2 \mathrm{H}_{2}+\mathrm{O}_{2} \\
\mathrm{CO}_{2}+4 \mathrm{H}_{2} \rightarrow \mathrm{CH}_{4}+2 \mathrm{H}_{2} \mathrm{O}
\end{gathered}
$$

The P2G integration with renewable energy makes it possible for their owners to use cheap electrical power to realize arbitrage by selling the generated synthetic natural gas in the gas market. Characteristically, the overall efficiency of electrolysis (power to hydrogen) and methanation (power to methane) processes is about $54-77 \%$ and $49-65 \%$ [53]. Due to technical and legislative limitations on the injected hydrogen into the natural gas network and reasons associated with ecological performance, methane is more profitable than injected hydrogen. The $\mathrm{CO}_{2}$ has a higher environmental impact compared to $\mathrm{CH}_{4}$. The main advantage of power to methane over other forms of power to $\mathrm{X}$ is consuming external $\mathrm{CO}$ or $\mathrm{CO}_{2}$ source during chemical reactions and decreasing the carbon emissions generated by the system for injecting into the natural gas network during peak hours. The overall perspective of both P2G processes is shown in Figure 1 and detailed in $[54,55]$.

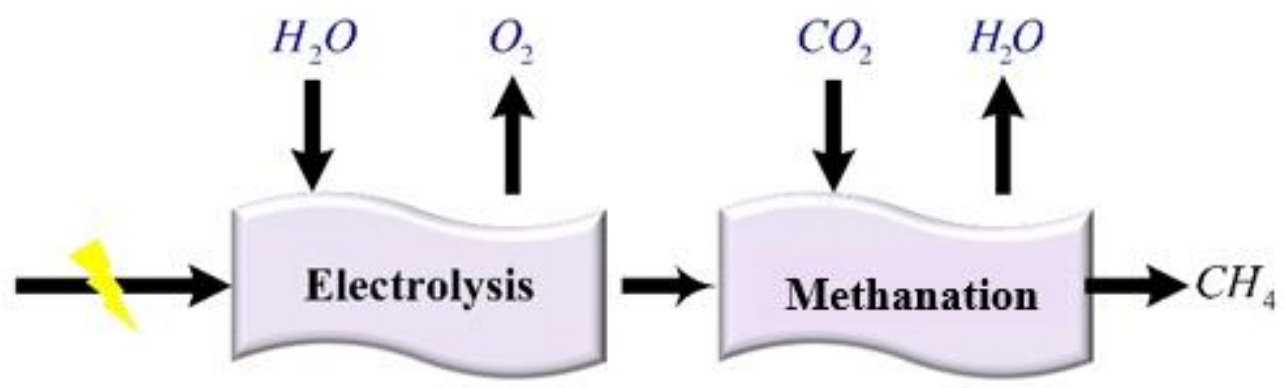

Figure 1. P2G schematic.

\subsection{Problem Description}

The overview of the proposed optimal scheduling for the MCMG coupled with P2G and CAES technologies aiming at minimizing daily cost and emission is depicted in Figure 2. The system operator purchases the electricity and natural gas from energy and gas markets under power market price variations. Then, P2G and CAES's operation set points along with DRP are determined to capture the uncertainty of the wind power and load demand, using the stochastic programming approach. Meanwhile, the operator simultaneously governs the tradeoff between economic and environmental targets [56]. Hence, the proposed structure is modeled as a multi-objective optimization problem and solved using weighted sum and fuzzy-based decision-making methods. Lastly, the model determines the optimal hourly purchased gas and power, optimal set points of CAES and P2G, wind spillage, and leverage DRP, as well as finding the optimal Pareto set pertained to minimum values of two conflicting objective functions. The mathematical problem formulation and methodology will be described later on. 


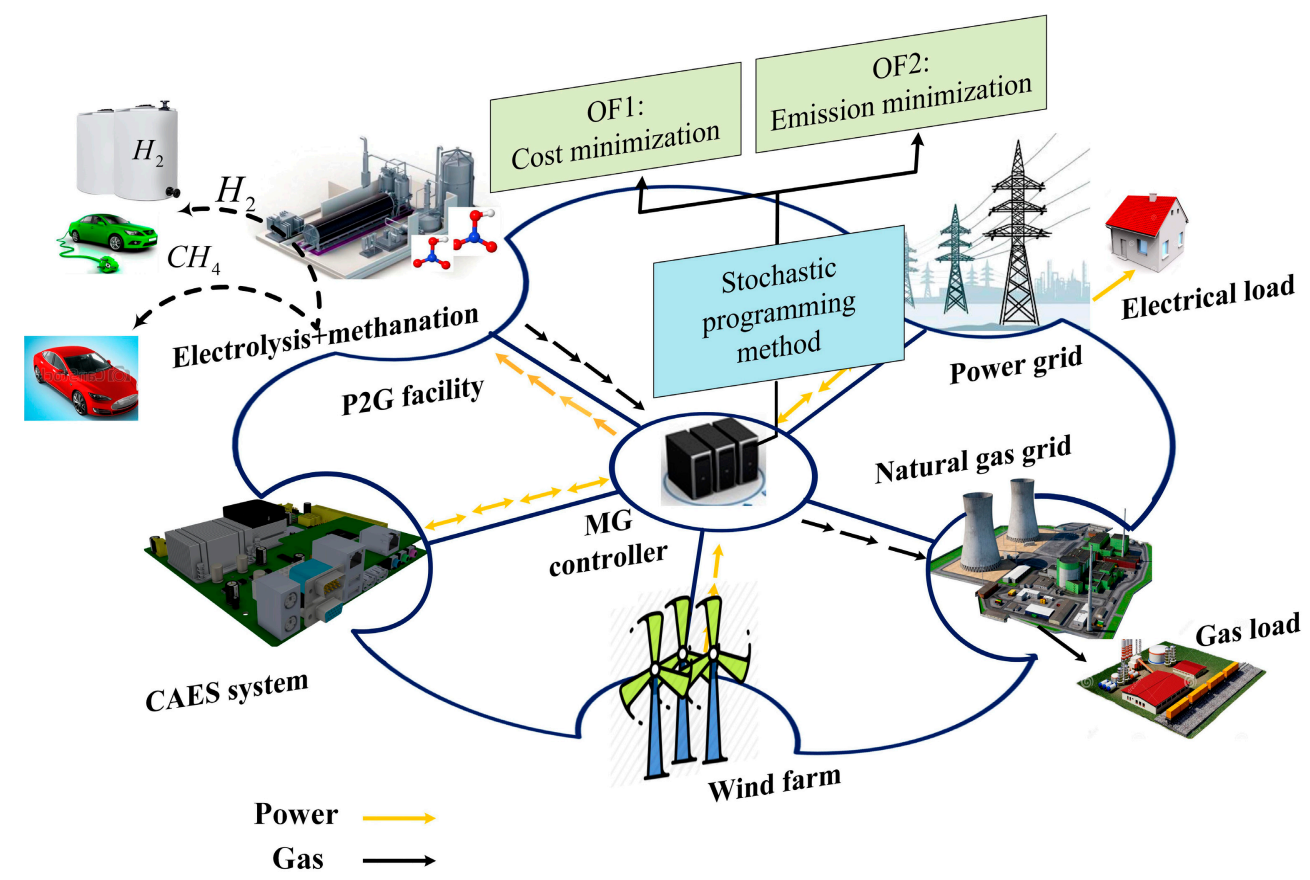

Figure 2. Schematic of the proposed MCMG system.

\section{Problem Formulation}

\subsection{Objective Functions}

- First Objective Function

As discussed, the MCMG system's objectives incorporated with coupled P2G and CAES are to reduce operation cost and $\mathrm{CO}_{2}$ pollution. First, the first objective function pertained to the total operation cost is modeled in Equation (3). The objective function consists of several terms. The cost of utility (purchased power and gas) from the power and gas markets are represented by two first terms, respectively. The CAES costs during multiple modes are given in the third, fourth, and fifth terms. The sixth term models the P2G operation cost during the gas-producing mode. The DRP cost is given in the seventh term. The wind power spillage cost is given in the last term of the objective function.

$$
\begin{aligned}
& O F_{1}=\sum_{s=1}^{N S} \pi_{s}\left(\sum_{t=1}^{N H}\left(\lambda_{t, s}^{e} P_{t, s}^{b u y}+\lambda_{h}^{g} G_{t, s}^{b u y}\right)+\right. \\
& \sum_{t=1}^{N T}\left(\left[P_{t, s}^{d i s} \times\left(H R^{d i s} \times \lambda_{t}^{g}+V O M^{\exp }\right)\right]+\left[P_{t, s}^{c h} \times V O M^{c}\right]\right) \\
& \left.+C^{\mathrm{P} 2 \mathrm{G}} G_{t, s}^{d i s}+C^{d r} \times d r_{t, s}+C^{w, s p} \times P_{t, s}^{w, s p}\right)
\end{aligned}
$$

\section{- Second objective function}

The second objective function aims to minimize the proposed integrated system's emission pollution modeled in Equation (4). The first and second terms of Equation (4) determine the emission tax resulted from purchasing power and gas energy carriers from the markets. It is worth noting that the P2G with capturing $\mathrm{CO}_{2}$ has a positive impact on the whole system from environmental perspectives. Thus, this characteristic reduces the pollutant emission of gas consumption given in the second term Equation (4). The last two terms of Equation (4) investigate the produced pollutant by CAES associated with discharge and simple-cycle modes.

$$
O F_{2}=\sum_{s=1}^{N S} \pi_{s}\left(\sum_{h=1}^{N T}\left(\gamma^{e} P_{t, s}^{b u y}+\gamma^{g}\left(G_{t, s}^{b u y}-G_{t, s}^{d i s}\right)+\gamma^{d i s} P_{t, s}^{d i s}+\gamma^{s i} P_{t, s}^{s i}\right)\right)
$$




\subsection{Constraints}

- P2G constraints

The overall chemical process of P2G to convert the surplus power into gas has been discussed in the previous section. The performance of $\mathrm{P} 2 \mathrm{G}$ in the MCMG scheduling is restricted by several constraints modeled as in (5)-(10). The electric power consumed by the P2G facility is limited in Equation (5). The maximum capacity of injected and stored gas of P2G storage is modeled by (6) and (7), respectively. The P2G performance is expressed as a function of injecting/storing natural gas in Equation (8). The natural gas storage is modeled in Equation (9).

$$
\begin{gathered}
0 \leq P_{t, s}^{\mathrm{P} 2 \mathrm{G}} \leq P^{\mathrm{P} 2 \mathrm{G}, \max } \\
0 \leq G_{t, s}^{d i s} \leq G^{d i s, \max } \\
G S^{\mathrm{min}} \leq G S_{t, s} \leq G S^{\max } \\
G_{t, s}^{G P}=\eta_{\mathrm{P} 2 \mathrm{G}} P_{t, s}^{\mathrm{P} 2 \mathrm{G}} \\
G S_{t, s}=G S_{t-1, s}+G_{t, s}^{G P}-G_{t, s}^{d i s}
\end{gathered}
$$

- Wind turbine constraints

The hourly power generated by the wind unit is a function of wind speed [57]. The hourly wind power is calculated based on Equation (10). The curtailed wind power is also limited to the wind availability and installed wind capacity as Equation (11).

$$
\begin{aligned}
P_{t, s}^{w}= \begin{cases}0 & V_{t, s}<V_{\text {cut-in }}, V_{t, s}>V_{\text {cut }- \text { out }} \\
P^{w, r} \times\left(\frac{V_{t, s}-V_{\text {cut }- \text { in }}}{V_{r}-V_{\text {cut }- \text { in }}}\right)^{3} & V_{\text {cut-in }} \leq V_{t, s} \leq V_{\text {rated }} \\
P^{w, r} & V_{\text {rated }} \leq V_{t, s} \leq V_{\text {cut } \text { out }}\end{cases} \\
P_{t, s}^{w, s p} \leq P_{t, s}^{w}
\end{aligned}
$$

- CAES constraints

A binary variable is defined for each CAES's operating mode, and it commonly operates in one mode at each hour, as in Equation (12). The power value limit for charging, discharging, and simple-cycle mode are shown in (13)-(15), respectively. The capacity of CAES is bounded by upper and lower values as Equation (16). Besides, the energy capacity of CAES is calculated by Equation (17).

$$
\begin{gathered}
u_{t, s}^{c h}+u_{t, s}^{d i s}+u_{t, s}^{s i} \leq 1 \\
0 \leq P_{t, s}^{c h} \leq P^{c h, \max } u_{t, s}^{c h} \\
0 \leq P_{t, s}^{d i s} \leq P^{d i s, \max } u_{t, s}^{d i s} \\
0 \leq P_{t, s}^{s i} \leq P^{s i, \max } u_{t, s}^{s i} \\
E^{\min } \leq E_{t, s} \leq E^{\max } \\
E_{t, s}=E_{t-1, s}+P_{t, s}^{c h}-\left(P_{t, s}^{d i s}+P_{t, s}^{s i}\right) \times E R
\end{gathered}
$$

- Demand response

The DRP shiftable strategy of [58] is employed in the model to smooth the load curve as in Equations (18)-(21).

$$
\begin{gathered}
P_{d, t, s}^{d r}=P_{d_{0}, t, s}+d r_{t, s} \\
d r_{t, s} \leq d r^{\max } \times P_{d_{0}, t, s} \\
d r_{t, s} \geq-d r^{\max } \times P_{d_{0}, t, s}
\end{gathered}
$$




$$
\sum_{t=1} d r_{t, s}=0
$$

- Energy balance constraints

The proposed MCMG supplies electrical and gas demands. The electricity and gas purchased from the power and gas markets are limited in Equations (22) and (23). The power and gas balance constraints are established by Equations (24) and (25). The gross heating value $(\mathrm{GHV})$ is used to convert the consumed natural gas by CAES into the corresponding gas value as in Equation (25) [59].

$$
\begin{gathered}
P_{t, s}^{b u y} \leq P^{b u y, \max } \\
G_{t, s}^{b u y} \leq G^{b u y, \max } \\
P_{t, s}^{b u y}+P_{t, s}^{w}-P_{t, s}^{w, s p}-P_{t, s}^{\mathrm{P} 2 \mathrm{G}}-P_{t, s}^{c h}+P_{t, s}^{d i s}+P_{t, s}^{s i}+d r_{t, s}-P_{d, t, s}=0 \\
G_{t, s}^{b u y}-\left(P_{t, s}^{d i s}+P_{t, s}^{s i}\right) \times E R \times G H V+G_{t, s}^{G P}-G_{d, t, s}=0
\end{gathered}
$$

\section{Solution Method}

The multi-objective scheduling of the proposed MCMG integrated with CAES, P2G, and DRP for supplying the gas and the electrical loads is solved using the weighted sum and fuzzy decision-making framework. The methodology of this approach is described as follows.

In the proposed MCMG scheduling integrated with several technologies with two conflicting objectives (cost and emission minimization), two coefficients $\left(K_{1}, K_{2}\right)$ are considered. Hence, the objective functions of Equations (3) and (4) can be reformed into a single objective as follows:

$$
\begin{aligned}
\operatorname{Min} O F= & K_{1} \times O F_{1}^{p u}+K_{2} \times O F_{2}^{p u} \\
& \text { s.t }:(5)-(25) \\
& K_{1}+K_{2}=1
\end{aligned}
$$

The fuzzy-based decision-making [60] is one of the techniques which can be applied to solve Equation (26). First, based on the min-max fuzzy approach, the min and max rates of two objectives (cost and emission) are defined [61]. Then, each objective's normalized form based on the min and max rates is calculated as Equations (29) and (30).

$$
\begin{aligned}
& O F_{1}^{p u}=\frac{O F_{1}-O F_{1}{ }^{\max }}{O F_{1}{ }^{\min }-O F_{1}{ }^{\max }} \\
& O F_{2}^{p u}=\frac{O F_{2}-O F_{2}{ }^{\max }}{O F_{2}{ }^{\min }-O F_{2}{ }^{\max }}
\end{aligned}
$$

In each iteration, the minimum amount between all existing objectives is determined using Equation (31). Lastly, the maximum amount between all obtained minimum normalized values is chosen as Equation (32).

$$
\begin{gathered}
f^{n}=\min \left\{f_{1}^{n}, f_{2}^{n}, \ldots \ldots, f_{z}^{n}\right\} \forall z=1, \ldots N_{z} \\
f^{\max }=\max \left\{\begin{array}{c}
f^{1} \\
f^{2} \\
\ldots \ldots \\
f^{N_{k}}
\end{array}\right\}
\end{gathered}
$$

\section{Simulation and Numerical Results}

A sample system consisting of a wind unit, electricity to P2G converter, and CAES in the presence of flexible loads is considered to assess the techno-economic analysis of 
an MCMG. Table 2 shows the specifications of CAES. Also, characteristics of P2G can be found in [62]. The DRP cost is $\$ 0.05 / \mathrm{kWh}$. The emission factor for the power purchased from the grid and load shedding cost is $0.54 \mathrm{~kg} / \mathrm{kWh}$ and $\$ 5 / \mathrm{kWh}$.

Table 2. Characteristics of CAES technology.

\begin{tabular}{|c|c|c|c|c|c|c|}
\hline $\begin{array}{c}\text { Min Charging/Discharging } \\
(\mathrm{kW})\end{array}$ & $\begin{array}{c}\text { Max Charging/Discharging } \\
\text { (kW) }\end{array}$ & $\begin{array}{c}\text { Max Simple Cycle } \\
(\mathrm{kW})\end{array}$ & $\begin{array}{l}\text { Capacity } \\
\text { (kWh) }\end{array}$ & $\begin{array}{c}\text { Energy ratio } \\
(\%)\end{array}$ & $\gamma^{d i s}$ & $\gamma^{s i}$ \\
\hline 0 & 150 & 150 & 650 & 80 & 0.36 & 0.36 \\
\hline
\end{tabular}

A scenario-based probabilistic approach is extended in the model to handle the variations of wind power, power price, and load demand. The Monte-Carlo simulation is utilized to generate a large number of scenarios, and then after, the generated scenarios are reduced to 10 using the backward selection technique in MATLAB to burden the complexity of computation. It should be noted that Weibull and Normal distribution function are used to model the wind power, load, and price uncertainties. More information can be found in $[63,64]$. This paper presumes that $10 \%$ of the total local demand contributes to DRP as in $[65,66]$. Figure 3 shows the power and gas market price curves. The load demand and wind power forecasts are shown in Figure 4.

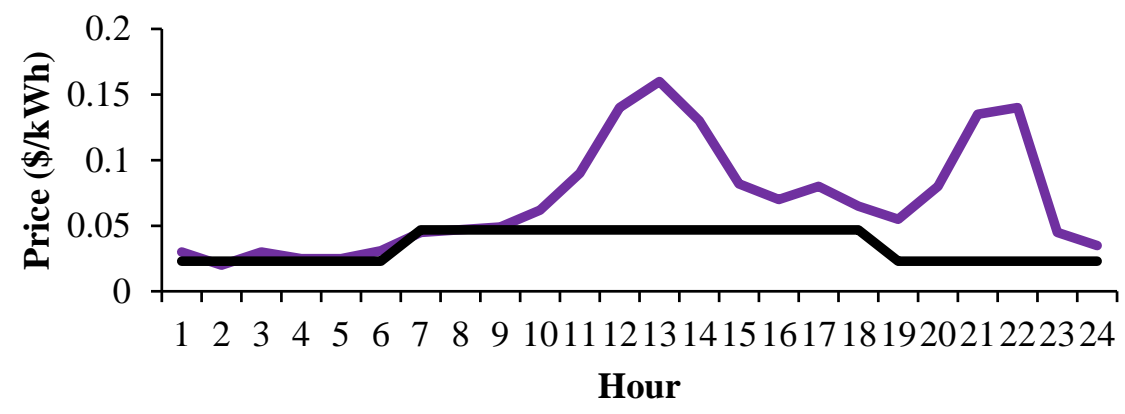

Power price $\longrightarrow$ Gas price

Figure 3. Market price curve.

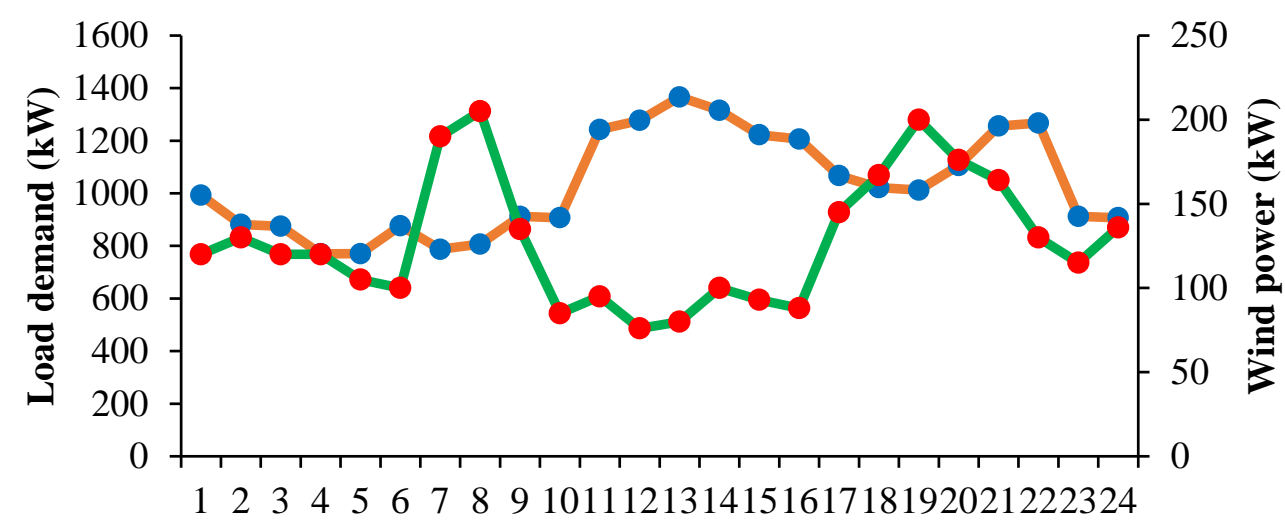

Hour

$\multimap$ Electrical demand $\multimap$ wind

Figure 4. Forecasted Load demand and wind power price curves.

To investigate the proposed eco-emission scheduling, two case study are discussed:

- Case 1: Coordinated operation of the MCMG in the presence of CAES and P2G, neglecting the environmental goal; 
- Case 2: Coordinated multi-objective scheduling of the MCMG in the presence of P2G and CAES.

\section{- Case 1}

The optimal operation of the proposed MCMG integrated with P2G, wind farm, and CAES technology is examined without considering the emission pollution limitation. The operator seeks to minimize total operation cost to optimally serve the local loads. The expected optimal scheduling of P2G in case 1 is shown in Figure 5. The P2G stores the surplus power at the first hours of the day (hours with lower energy prices). The stored power is converted into natural gas and injected into the grid at 11-13,15, and 17-19, as shown in Figure 5. Herein, the operator contributes to more economic savings stemmed from the economical purchase of gas during the discharge mode of the P2G. Besides, more wind power is integrated into the grid using $\mathrm{P} 2 \mathrm{G}$, which results in lower wind energy curtailment.

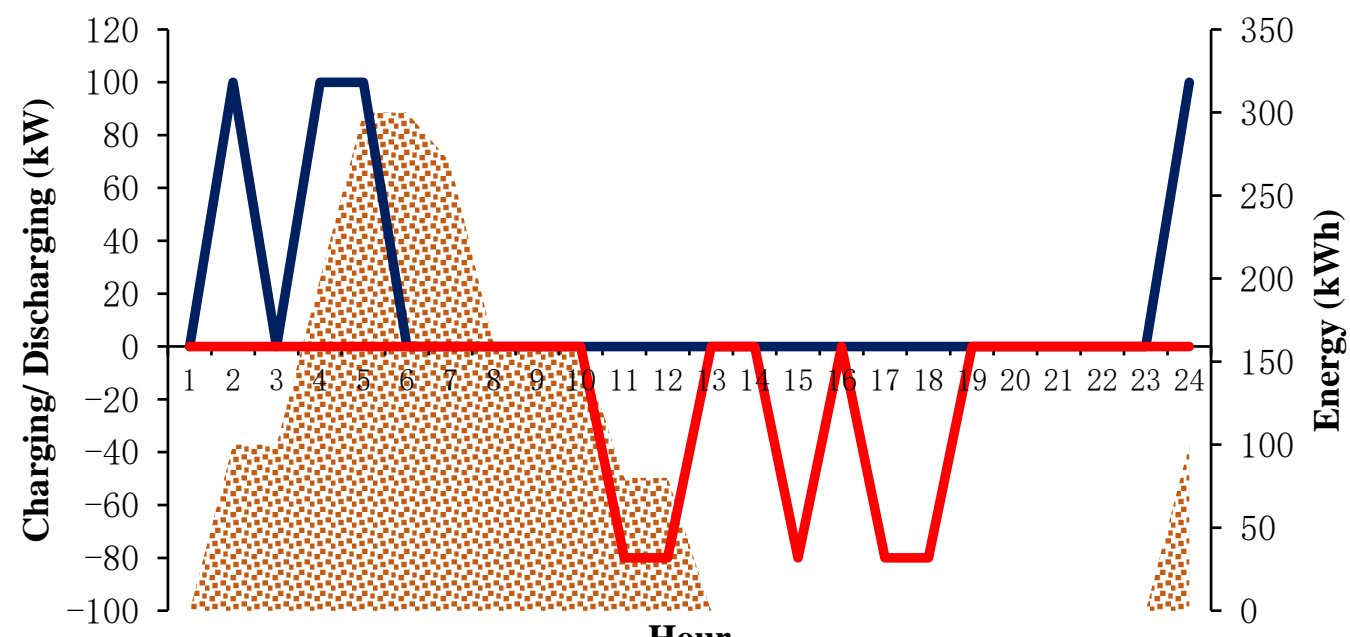

Hour

ass Energy capacity $\longrightarrow$ Power consumed $\quad$ Gas produced

Figure 5. Optimal operation of P2G in Case 1.

The expected optimal operation of CAES technology in case 1 is shown in Figure 6. As can be seen, CAES does not operate in the simple-cycle mode. CAES is charged during off-peak hours (1-5 and 16-18). When the power market price reaches higher values, CAES is discharged and supplies the local load. The CAES's energy capacity is also shown in Figure 6, which follows the optimal charging/discharging scheme. 


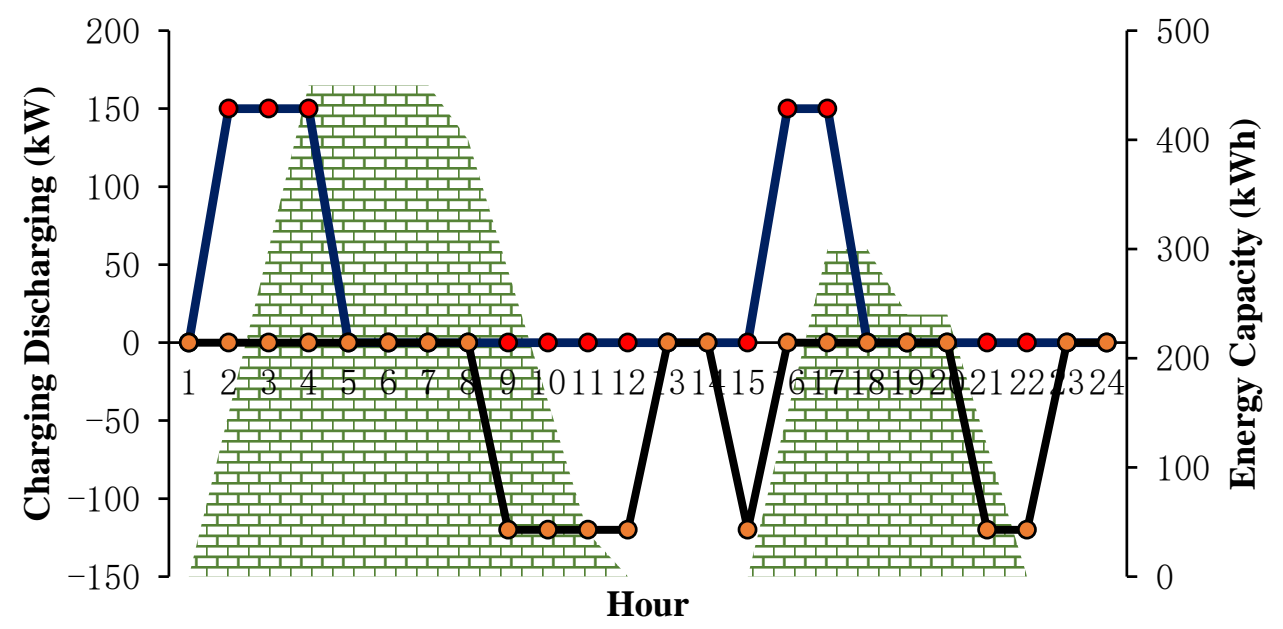

두라 Energy $\quad-$ Charging mode $\quad-$ Discharging mode

Figure 6. Optimal operation of CAES in Case 1.

The hourly power and natural gas purchased from the power and gas market are shown in Figure 7 for case 1. In this case, the emission limitation is overlooked; thus, the operator neglects the environmental constraints and contributes to economic savings. As illustrated, the purchased power and gas curves follow the inverse behavior. This phenomenon occurs because of the energy price fluctuations. For periods $12-15$, when the system requires more electricity, the operator purchases more power from the power market. Hence, the gas purchase is reduced to contribute to more economic benefits. However, the required natural gas at this period is mainly provided by $\mathrm{P} 2 \mathrm{G}$ that is operating in discharging mode and subsequently reducing MCMGs' reliance on the gas network.

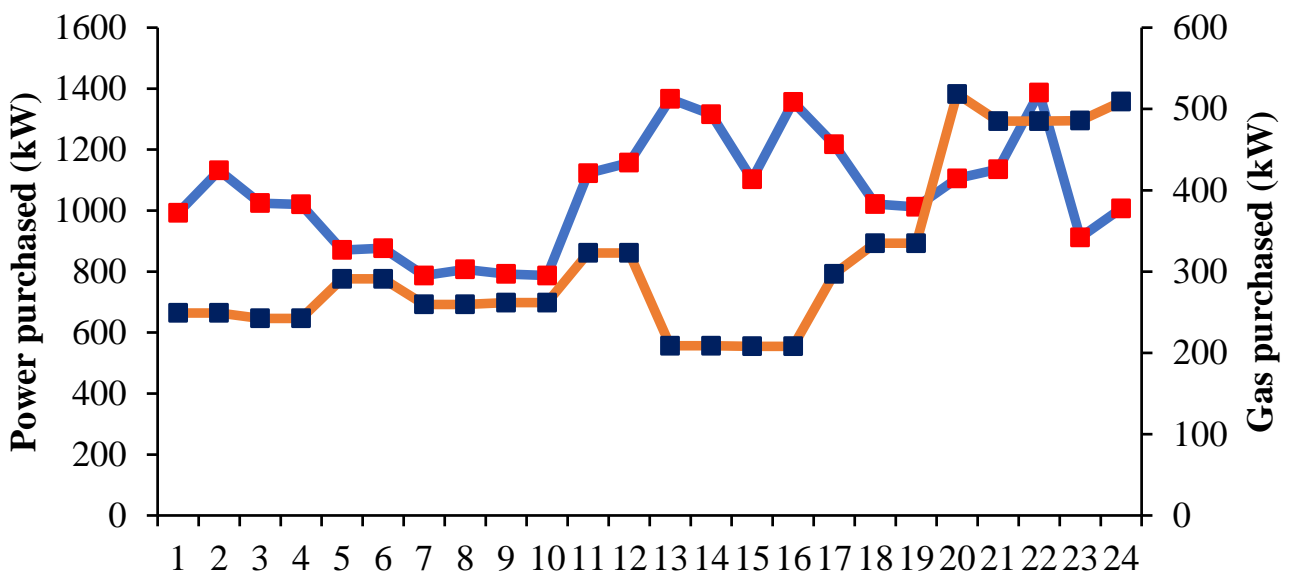

Hour

$$
- \text { Power purchased } \quad-\text { Gas purchased }
$$

Figure 7. Optimal purchased power and gas in Case 1.

The DRP, based on the shifting capability, is used in this paper to increase system flexibility. The load curve before and after DRP implementation is shown in Figure 8. Herein, the DRP does not change the total value of the load but smooths the load curve. In other words, DRP shifts the load demand from peak to off-peak hours. As can be seen, employing DRP results in alleviating the demands at hours 11-16 and 20-22 and consequently economic savings. As shown in Figure 9, purchasing power during peak 
hours $11-15$ and $20-22$ is reduced after DRP implementation, whereas the purchasing power at valleys is increased.

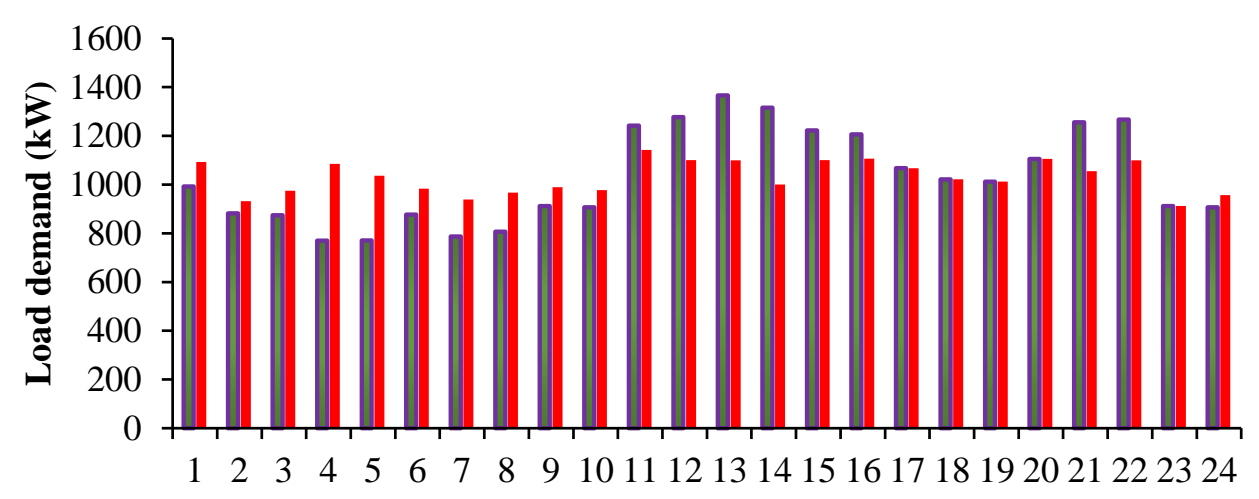

Hour

\section{$\square$ Before DRP $\quad$ After DRP}

Figure 8. Load demand before and after leveraging DRP in case 1.

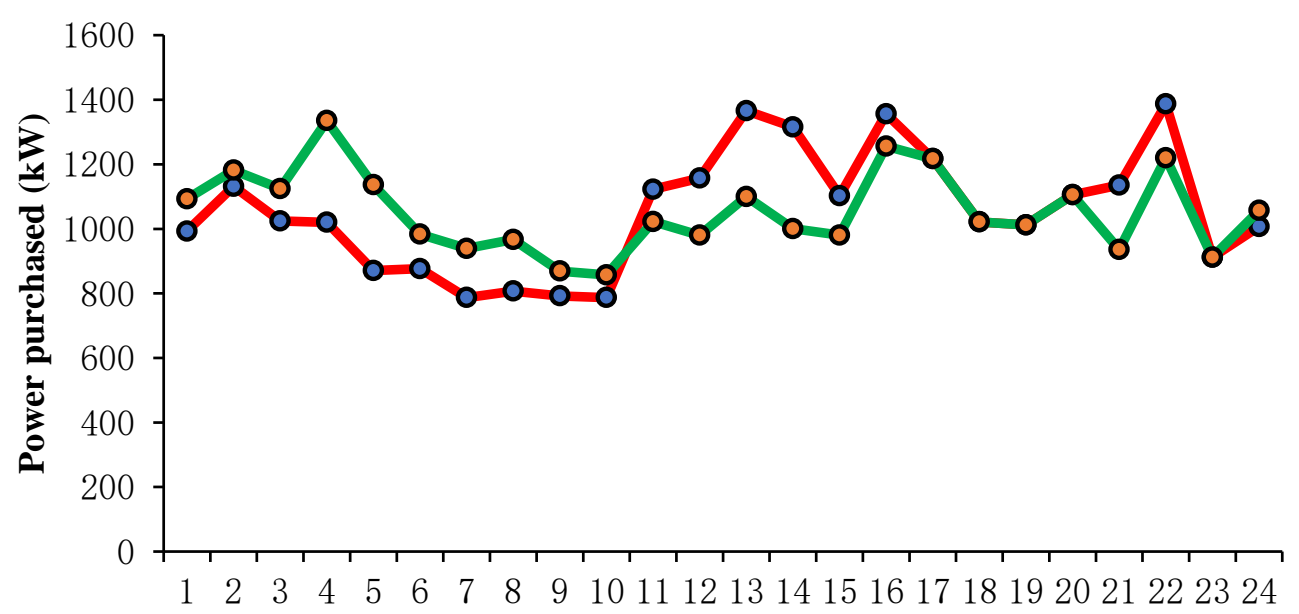

Hour

\section{- - Purchased power before DRP $\quad-$-Purchased power after DRP}

Figure 9. Comparison of power purchased before and after DRP.

In case 1 , the value of the objective function (3) is listed in Table 3 to scrutinize the effects of CAES, P2G, and DRP on the system's operation cost. The results advocate the importance of $\mathrm{P} 2 \mathrm{G}$ technology in reducing the cost by $3.4 \%$. More importantly, the operation cost is reduced by $5.25 \%$ from $\$ 7296.25$ to $\$ 6912.73$ in the presence of P2G, CAES, and DRP.

Table 3. Effects of the integrated technology on the economic saving for case 1.

\begin{tabular}{cccc}
\hline & CAES & CAES and P2G & Integrated CAES, P2G, and DRP \\
\hline $\operatorname{Cost}(\$)$ & 7296.25 & 7048.16 & 6912.73 \\
\hline
\end{tabular}

\section{- Case 2}

The optimal performance of the MCMG system in the presence of several technologies is examined in this case, considering both environmental and economic perspectives. As discussed, the proposed model is formulated as a multi-objective problem to minimize 
both objectives. To this end, the weighted sum technique is used to find Pareto solutions to reduce the daily emission and operation cost in the proposed multi-objective model. Pareto solutions are given in Table 4. According to the obtained Pareto solutions, the min-max fuzzy technique is implemented to normalize $O F_{1}$ and $O F_{2}$ in addition to presenting the tradeoff between two objective functions. Besides, the obtained solutions are studied in Figure 10. According to the obtained solutions in Table 4 and Figure 10, iteration number 5 is selected as an optimal solution based on the fuzzy approach. The selected solution (iteration number 5) is given as $\$ 7456.81$ and $9656.11 \mathrm{~kg}$, respectively, for the system's operation cost and emission pollution in case 2 .

Table 4. Pareto solution for the model in case 2.

\begin{tabular}{cccccccc}
\hline Iteration & $\boldsymbol{K}_{\mathbf{1}}$ & $\boldsymbol{K}_{\mathbf{2}}$ & $\boldsymbol{O F}_{\mathbf{1}}(\mathbf{\$})$ & $\boldsymbol{O F}_{\mathbf{2}}(\boldsymbol{k g})$ & $\boldsymbol{O F}_{\mathbf{1}}^{p \boldsymbol{u}}$ & $\boldsymbol{O F}_{\mathbf{2}}^{p \boldsymbol{u}}$ & $\boldsymbol{\operatorname { m i n }}\left\{\boldsymbol{f}_{\mathbf{1}}^{n}, \boldsymbol{f}_{\mathbf{2}}^{\boldsymbol{n}}\right\}$ \\
\hline 1 & 1 & 0 & 6912.73 & 9976.45 & 1 & 0 & 0 \\
2 & 0.9 & 0.1 & 6989.05 & 9865.02 & 0.914 & 0.146 & 0.146 \\
3 & 0.8 & 0.2 & 7047.31 & 9815.96 & 0.849 & 0.212 & 0.212 \\
4 & 0.7 & 0.3 & 7107.95 & 9752.41 & 0.7811 & 0.294 & 0.294 \\
5 & 0.6 & 0.4 & 7456.81 & 9656.11 & 0.39 & 0.421 & 0.39 \\
6 & 0.5 & 0.5 & 7497.44 & 9604.14 & 0.344 & 0.489 & 0.344 \\
7 & 0.4 & 0.6 & 7600.06 & 9547.02 & 0.229 & 0.564 & 0.229 \\
8 & 0.3 & 0.7 & 7659.35 & 9405.3 & 0.162 & 0.75 & 0.162 \\
9 & 0.2 & 0.8 & 7783.13 & 9374.25 & 0.04 & 0.791 & 0.04 \\
10 & 0.1 & 0.9 & 7792.52 & 9281.91 & 0.013 & 0.912 & 0.013 \\
11 & 0 & 1 & 7804.67 & 9215.55 & 0 & 1 & 0 \\
\hline
\end{tabular}

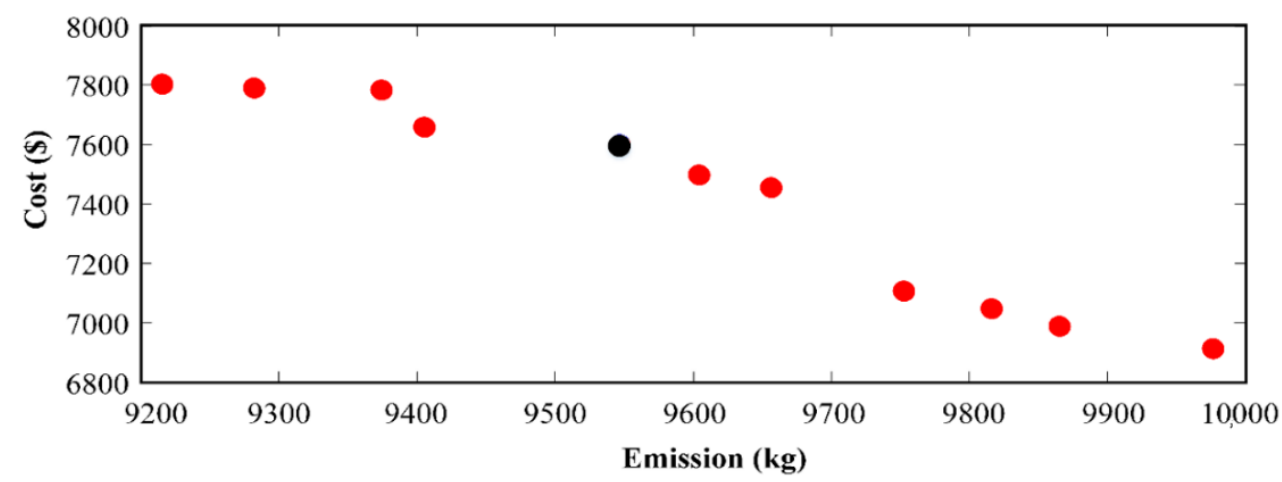

Figure 10. The Pareto optimal front for the bi-objective problem in case 2.

In case 2, the CAES scheme is shown in Figure 11. The results denote that the CAES operates in the simple-cycle mode when there is an increase in loads, e.g., hours 13 and 14. Purchasing intense-carbonized power from the grid is the dominant reason for utilizing the CAES fed by lower carbonized natural gas. In other words, the operator tends to generate power by the CAES in simple-cycle mode instead of purchasing power, contributing to environmental and economic goals. 


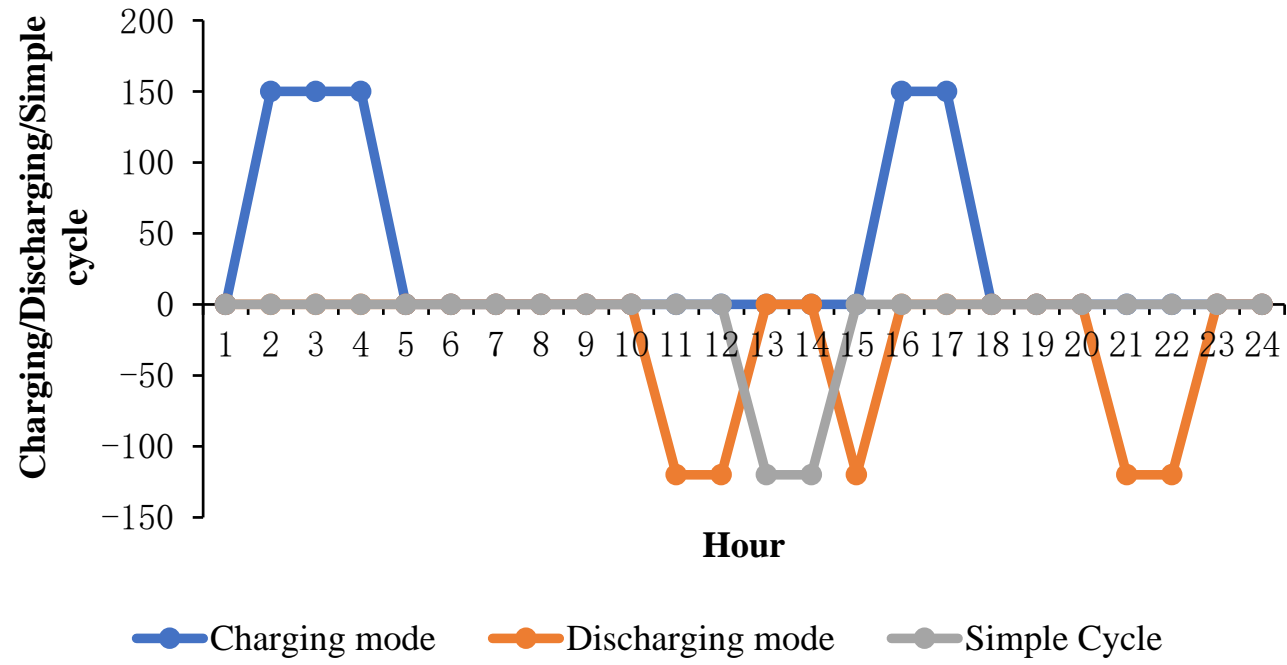

Figure 11. Optimal operation schedule of CAES in case 2.

P2G has impressive effects on $\mathrm{CO}_{2}$ capturing as given in objective function Equation (4). P2G facilitates the integration of wind power in the system. In this way, the surplus power is converted into natural gas and injected into the system in gas peak hours. As given in objective function (4), natural gas is one of the main emission pollution resources. Meanwhile, the P2G captures the $\mathrm{CO}_{2}$ gas and mixes it with the produced hydrogen. In this way, the $\mathrm{CH}_{4}$ is produced and injected into the system. Thus, $\mathrm{P} 2 \mathrm{G}$ technology has a unique role in emission pollution minimization. The effects of CAES, P2G, and DRP integration on the system's operation cost and emission pollution under the multi-objective framework are shown in Table 5. In case 2, the integration of CAES, P2G, and DRP would result in cost and pollution reduction of up to $14.2 \%$ and $9.6 \%$. This table proves the advantages of the integrated energy system from emission reduction and cost improvement.

Table 5. Effects of smart grid technologies on the operation cost and emission pollution in case 2.

\begin{tabular}{cccc}
\hline & CAES & CAES and P2G & Integrated CAES, P2G, and DRP \\
\hline Cost $(\$)$ & 8690.1 & 8129.37 & 7456.81 \\
\hline Emission $(\mathrm{kg})$ & 11364.81 & $10,681.53$ & 9656.11 \\
\hline
\end{tabular}

\section{Conclusions}

Supplying energy to consumers in power grids plays a major role in increasing greenhouse gas emissions. Utilizing high-efficiency technologies along with managing energy networks can play an effective role in reducing pollution emissions and system operation costs. Thus, this paper studied the optimal operation of a hybrid MCMG in the presence of CAES and P2G converter with the aim of minimizing the operation costs and pollution in a multi-objective framework. Electricity and natural gas were considered as inputs for the proposed MCMG to supply local loads. The proposed CAES can work in different modes, including simple-cycle and charging/discharging modes for supplying loads in critical periods as a generator. The DRP, based on the shifting strategy, was extended to manage the load curve and improve eco-emissions benefits. The proposed multi-objective model was solved by the weighted sum and min-max fuzzy approach. Numerical results were discussed for two cases, and the effects of several smart grid technologies on the operation cost and emission pollution were analyzed. Results revealed that integrating $\mathrm{P} 2 \mathrm{G}$ as a vital technology for capturing $\mathrm{CO}_{2}$ and mixing with $\mathrm{H}_{2}$ has a substantial role in greenhouse gas emission mitigation. Lastly, the integration of CAES, P2G, and DRP results in up to $14.2 \%$ and $9.6 \%$ reduction in operation cost and pollution, respectively. 
In summary, this model enables the energy systems to couple various energy carriers, which yields various benefits from operational and economic perspectives to coordination between the interconnected multi-carrier microgrid communities. Indeed, the coordination by the centralized optimization of the proposed network brings the system into an optimum situation, particularly when an incident occurs in the network. Moreover, the probabilistic method can increase the trustworthiness of the optimal solution by considering more uncertain parameters.

Author Contributions: K.H.: writing—original draft, visualization. S.S.: resources, data curation, investigation. S.E.: software, methodology. M.A.: conceptualization, formal analysis, validation, writing -review and editing. H.G.: project administration. All authors have read and agreed to the published version of the manuscript.

Funding: This research received no external funding.

Informed Consent Statement: Not applicable.

Data Availability Statement: Data are available with authors upon request.

Conflicts of Interest: The authors declare no conflict of interest.

\section{Nomenclature}

\begin{tabular}{|c|c|}
\hline \multicolumn{2}{|l|}{ Indices } \\
\hline$t$ & time \\
\hline$s$ & scenario \\
\hline \multicolumn{2}{|c|}{ Constants } \\
\hline$H R_{\text {dis }}$ & HR of CAES in discharging \\
\hline$H R_{s i}$ & HR of CAES in simple-cycle \\
\hline$V O M^{c}$ & Operation costs of CAES in charging \\
\hline$V O M^{\exp }$ & Operation costs of CAES in discharging \\
\hline$P^{c, \max }$ & Maximum power charged of CAES \\
\hline$P^{d i s, \max }$ & Maximum power discharge of CAES \\
\hline$P^{s i, \max }$ & Maximum power generation by CAES \\
\hline$E_{\min }$ & The minimum energy capacity of CAES \\
\hline$E_{\max }$ & The maximum energy capacity of CAES \\
\hline$E_{\text {int }}$ & The initial Energy of CAES \\
\hline$E R$ & CAES energy ratio \\
\hline$C^{\mathrm{P} 2 \mathrm{G}}$ & Operation cost of $\mathrm{P} 2 \mathrm{G}$ during the gas-producing mode \\
\hline$G^{d i s, \max }$ & Maximum P2G power operation \\
\hline$G S^{\min }$ & Minimum gas capacity of $\mathrm{P} 2 \mathrm{G}$ \\
\hline$G S^{\max }$ & Maximum gas capacity of $\mathrm{P} 2 \mathrm{G}$ \\
\hline$\gamma^{e}$ & Emission coefficient for power purchasing \\
\hline$\gamma^{g}$ & Emission coefficient for gas purchasing \\
\hline$\gamma^{\text {dis }}$ & Emission coefficient for CAES during discharging mode \\
\hline$\gamma^{s i}$ & Emission coefficient for CAES during simple-cycle mode \\
\hline$\eta_{\mathrm{P} 2 \mathrm{G}}$ & P2G efficiency \\
\hline$C^{w, s p}$ & Cost of wind spillage \\
\hline \multicolumn{2}{|l|}{ Variables } \\
\hline$\lambda_{t, s}^{e}$ & Electricity price forecast at time $t$ and scenario $s$ \\
\hline$\lambda_{t}^{d^{s}}$ & Gas price at time $t$ \\
\hline$P_{t, s}^{w p}$ & Total produced energy by wind turbine \\
\hline$\pi_{k}$ & Probability of scenario \\
\hline$P_{t s}^{\text {dis }}$ & Produced power by CAES in discharging mode \\
\hline$P_{t, s}^{c h}$ & Power charged by CAES in charging mode \\
\hline$P_{t s}^{c h}$ & Power produced by CAES during simple-cycle \\
\hline
\end{tabular}




$\begin{array}{ll}E_{t, s} & \text { Capacity of CAES } \\ P_{t, s}^{\mathrm{P} 2 \mathrm{G}} & \text { Power consumed by P2G } \\ G_{t, s}^{G P} & \text { Gas production by P2G facility } \\ G_{t, s}^{d i s} & \text { The consumed power by P2G facility at time t and scenario s } \\ G S_{t, s} & \text { The capacity of P2G's tanks at time t and scenario s } \\ G_{t, s}^{\text {buy }} & \text { Purchased gas from the gas market at time } t \text { and scenario s } \\ P_{t, s}^{\text {buy }} & \text { Purchased power from the electricity market } \\ P_{t, s}^{w, s p} & \text { Wind power spillage } \\ u_{t, s}^{c h} / u_{t, s}^{\text {dis }} / u_{t, s}^{s i} & \text { CAES status in charging/discharging modes }\end{array}$

\section{References}

1. Azimian, M.; Amir, V.; Javadi, S. Economic and Environmental Policy Analysis for Emission-Neutral Multi-Carrier Microgrid Deployment. Appl. Energy 2020, 277, 115609. [CrossRef]

2. IEA. Deep Energy Transformation Needed by 2050 to Limit Rise in Global Temperature. IEA, Paris. 2019. Available online: https:/ / www.iea.org/ reports (accessed on 15 March 2021).

3. Hemmati, M.; Abapour, M.; Mohammadi-Ivatloo, B.; Anvari-Moghaddam, A. Optimal Operation of Integrated Electrical and Natural Gas Networks with a Focus on Distributed Energy Hub Systems. Sustainability 2020, 12, 8320. [CrossRef]

4. Farah, A.; Hassan, H.; M Abdelshafy, A.; M Mohamed, A. Optimal Scheduling of Hybrid Multi-Carrier System Feeding Electrical/Thermal Load Based on Particle Swarm Algorithm. Sustainability 2020, 12, 4701. [CrossRef]

5. IEA. World energy outlook 2011. Int. Energy Agency, IEA, Paris. 2011. Available online: https://www.iea.org/reports/worldenergy-outlook-2011 (accessed on 15 March 2021).

6. $\quad$ Ogland-Hand, J.D.; Bielicki, J.M.; Wang, Y.; Adams, B.M.; Buscheck, T.A.; Saar, M.O. The value of bulk energy storage for reducing $\mathrm{CO} 2$ emissions and water requirements from regional electricity systems. Energy Convers. Manag. 2019, 181, 674-685. [CrossRef]

7. Yu, D.; Wang, J.; Li, D.; Jermsittiparsert, K.; Nojavan, S. Risk-averse stochastic operation of a power system integrated with hydrogen storage system and wind generation in the presence of demand response program. Int. J. Hydrogen Energy 2019, 44, 31204-31215. [CrossRef]

8. Hemmati, M.; Mohammadi-Ivatloo, B.; Abapour, M.; Anvari-Moghaddam, A. Optimal Chance-Constrained Scheduling of Reconfigurable Microgrids Considering Islanding Operation Constraints. IEEE Syst. J. 2020, 14, 5340-5349. [CrossRef]

9. Ji, W.; Zhou, Y.; Sun, Y.; Zhang, W.; An, B.; Wang, J. Thermodynamic analysis of a novel hybrid wind-solar-compressed air energy storage system. Energy Convers. Manag. 2017, 142, 176-187. [CrossRef]

10. Luo, X.; Wang, J.; Krupke, C.; Wang, Y.; Sheng, Y.; Li, J.; Xu, Y.; Wang, D.; Miao, S.; Chen, H. Modelling study, efficiency analysis and optimisation of large-scale Adiabatic Compressed Air Energy Storage systems with low-temperature thermal storage. Appl. Energy 2016, 162, 589-600. [CrossRef]

11. Zhang, X.; Xu, Y.; Zhou, X.; Zhang, Y.; Li, W.; Zuo, Z.; Guo, H.; Huang, Y.; Chen, H. A near-isothermal expander for isothermal compressed air energy storage system. Appl. Energy 2018, 225, 955-964. [CrossRef]

12. Budt, M.; Wolf, D.; Span, R.; Yan, J. A review on compressed air energy storage: Basic principles, past milestones and recent developments. Appl. Energy 2016, 170, 250-268. [CrossRef]

13. Shafiee, S.; Zareipour, H.; Knight, A. Considering thermodynamic characteristics of a CAES facility in self-scheduling in energy and reserve markets. IEEE Trans. Smart Grid 2016, 9, 3476-3485. [CrossRef]

14. Castellani, B.; Morini, E.; Nastasi, B.; Nicolini, A.; Rossi, F. Small-scale compressed air energy storage application for renewable energy integration in a listed building. Energies 2018, 11, 1921. [CrossRef]

15. Akbari, E.; Hooshmand, R.-A.; Gholipour, M.; Parastegari, M. Stochastic programming-based optimal bidding of compressed air energy storage with wind and thermal generation units in energy and reserve markets. Energy 2019, 171, 535-546. [CrossRef]

16. Ghaljehei, M.; Ahmadian, A.; Golkar, M.A.; Amraee, T.; Elkamel, A. Stochastic SCUC considering compressed air energy storage and wind power generation: A techno-economic approach with static voltage stability analysis. Int. J. Electr. Power Energy Syst. 2018, 100, 489-507. [CrossRef]

17. Aliasghari, P.; Zamani-Gargari, M.; Mohammadi-Ivatloo, B. Look-ahead risk-constrained scheduling of wind power integrated system with compressed air energy storage (CAES) plant. Energy 2018, 160, 668-677. [CrossRef]

18. Ghalelou, A.N.; Fakhri, A.P.; Nojavan, S.; Majidi, M.; Hatami, H. A stochastic self-scheduling program for compressed air energy storage (CAES) of renewable energy sources (RESs) based on a demand response mechanism. Energy Convers. Manag. 2016, 120, 388-396. [CrossRef]

19. Xu, X.; Hu, W.; Cao, D.; Huang, Q.; Liu, W.; Liu, Z.; Chen, Z.; Lund, H. Designing a standalone wind-diesel-CAES hybrid energy system by using a scenario-based bi-level programming method. Energy Convers. Manag. 2020, 211, 112759. [CrossRef]

20. Shafiee, S.; Zareipour, H.; Knight, A.M.; Amjady, N.; Mohammadi-Ivatloo, B. Risk-constrained bidding and offering strategy for a merchant compressed air energy storage plant. IEEE Trans. Power Syst. 2016, 32, 946-957. [CrossRef]

21. Daryabari, M.K.; Keypour, R.; Golmohamadi, H. Stochastic energy management of responsive plug-in electric vehicles characterizing parking lot aggregators. Appl. Energy 2020, 279, 115751. [CrossRef] 
22. Lamagna, M.; Nastasi, B.; Groppi, D.; Rozain, C.; Manfren, M.; Garcia, D.A. Techno-economic assessment of reversible Solid Oxide Cell integration to renewable energy systems at building and district scale. Energy Convers. Manag. 2021, $235,113993$. [CrossRef]

23. Zeng, S.; Gu, J.; Yang, S.; Zhou, H.; Qian, Y. Comparison of techno-economic performance and environmental impacts between shale gas and coal-based synthetic natural gas (SNG) in China. J. Clean. Prod. 2019, 215, 544-556. [CrossRef]

24. Lewandowska-Bernat, A.; Desideri, U. Opportunities of power-to-gas technology in different energy systems architectures. Appl. Energy 2018, 228, 57-67. [CrossRef]

25. Liu, G.; Starke, M.; Xiao, B.; Zhang, X.; Tomsovic, K. Microgrid optimal scheduling with chance-constrained islanding capability. Electr. Power Syst. Res. 2017, 145, 197-206. [CrossRef]

26. Baumann, C.; Schuster, R.; Moser, A. Economic potential of power-to-gas energy storages. In Proceedings of the 201310 th International Conference on the European Energy Market (EEM), Stockholm, Sweden, 27-31 May 2013; pp. 1-6.

27. Yang, J.; Zhang, N.; Cheng, Y.; Kang, C.; Xia, Q. Modeling the Operation Mechanism of Combined P2G and Gas-Fired Plant With CO 2 Recycling. IEEE Trans. Smart Grid 2018, 10, 1111-1121. [CrossRef]

28. He, C.; Liu, T.; Wu, L.; Shahidehpour, M. Robust coordination of interdependent electricity and natural gas systems in day-ahead scheduling for facilitating volatile renewable generations via power-to-gas technology. J. Mod. Power Syst. Clean Energy 2017, 5 , 375. [CrossRef]

29. Zhou, S.; Sun, K.; Wu, Z.; Gu, W.; Wu, G.; Li, Z.; Li, J. Optimized operation method of small and medium-sized integrated energy system for P2G equipment under strong uncertainty. Energy 2020, 199, 117269. [CrossRef]

30. Ding, X.; Sun, W.; Harrison, G.P.; Lv, X.; Weng, Y. Multi-objective optimization for an integrated renewable, power-to-gas and solid oxide fuel cell/gas turbine hybrid system in microgrid. Energy 2020, 213, 118804. [CrossRef]

31. Ju, L.; Zhao, R.; Tan, Q.; Lu, Y.; Tan, Q.; Wang, W. A multi-objective robust scheduling model and solution algorithm for a novel virtual power plant connected with power-to-gas and gas storage tank considering uncertainty and demand response. Appl. Energy 2019, 250, 1336-1355. [CrossRef]

32. Wang, C.; Dong, S.; Xu, S.; Yang, M.; He, S.; Dong, X.; Liang, J. Impact of power-to-gas cost characteristics on power-gas-heating integrated system scheduling. IEEE Access 2019, 7, 17654-17662. [CrossRef]

33. Milani, D. Renewable Energy Integration in Combined Cooling, Heating, and Power (CCHP) Processes. In Polygeneration with Polystorage for Chemical and Energy Hubs; Elsevier: Amsterdam, The Netherlands, 2019; pp. 459-491.

34. Liu, W.; Gu, W.; Wang, J.; Yu, W.; Xi, X. Game theoretic non-cooperative distributed coordination control for multi-microgrids. IEEE Trans. Smart Grid 2018, 9, 6986-6997. [CrossRef]

35. Orecchini, F.; Santiangeli, A. Beyond smart grids-The need of intelligent energy networks for a higher global efficiency through energy vectors integration. Int. J. Hydrogen Energy 2011, 36, 8126-8133. [CrossRef]

36. Nazari-Heris, M.; Mirzaei, M.A.; Mohammadi-Ivatloo, B.; Marzband, M.; Asadi, S. Economic-environmental effect of power to gas technology in coupled electricity and gas systems with price-responsive shiftable loads. J. Clean. Prod. 2020, 244, 118769. [CrossRef]

37. Jiang, R.; Yin, H.; Chen, B.; Xu, Y.; Yang, M.; Yang, X. Multi-objective assessment, optimization and application of a grid-connected combined cooling, heating and power system with compressed air energy storage and hybrid refrigeration. Energy Convers. Manag. 2018, 174, 453-464. [CrossRef]

38. Wang, X.; Yang, C.; Huang, M.; Ma, X. Multi-objective optimization of a gas turbine-based CCHP combined with solar and compressed air energy storage system. Energy Convers. Manag. 2018, 164, 93-101. [CrossRef]

39. Golmohamadi, H.; Larsen, K.G.; Jensen, P.G.; Hasrat, I.R. Optimization of power-to-heat flexibility for residential buildings in response to day-ahead electricity price. Energy Build. 2021, 232, 110665. [CrossRef]

40. Soltani, Z.; Ghaljehei, M.; Gharehpetian, G.; Aalami, H. Integration of smart grid technologies in stochastic multi-objective unit commitment: An economic emission analysis. Int. J. Electr. Power Energy Syst. 2018, 100, 565-590. [CrossRef]

41. Ghasemi, A.; Enayatzare, M. Optimal energy management of a renewable-based isolated microgrid with pumped-storage unit and demand response. Renew. Energy 2018, 123, 460-474. [CrossRef]

42. Li, Y.; Wang, J.; Han, Y.; Zhao, Q.; Fang, X.; Cao, Z. Robust and opportunistic scheduling of district integrated natural gas and power system with high wind power penetration considering demand flexibility and compressed air energy storage. J. Clean. Prod. 2020, 256, 120456. [CrossRef]

43. Kiptoo, M.K.; Lotfy, M.E.; Adewuyi, O.B.; Conteh, A.; Howlader, A.M.; Senjyu, T. Integrated approach for optimal technoeconomic planning for high renewable energy-based isolated microgrid considering cost of energy storage and demand response strategies. Energy Convers. Manag. 2020, 215, 112917. [CrossRef]

44. Zhang, L.; Kuang, J.; Sun, B.; Li, F.; Zhang, C. A two-stage operation optimization method of integrated energy systems with demand response and energy storage. Energy 2020, 208, 118423. [CrossRef]

45. Bitaraf, H.; Rahman, S. Reducing curtailed wind energy through energy storage and demand response. IEEE Trans. Sustain. Energy 2017, 9, 228-236. [CrossRef]

46. Hemmati, M.; Mirzaei, M.A.; Abapour, M.; Zare, K.; Mohammadi-ivatloo, B.; Mehrjerdi, H.; Marzband, M. EconomicEnvironmental Analysis of Combined Heat and Power-Based Reconfigurable Microgrid Integrated with Multiple Energy Storage and Demand Response Program. Sustain. Cities Soc. 2021, 69, 102790. [CrossRef] 
47. Heidari, A.; Mortazavi, S.; Bansal, R. Stochastic effects of ice storage on improvement of an energy hub optimal operation including demand response and renewable energies. Appl. Energy 2020, 261, 114393. [CrossRef]

48. Habibifar, R.; Khoshjahan, M.; Ghasemi, M.A. Optimal Scheduling of Multi-Carrier Energy System Based on Energy Hub Concept Considering Power-to-Gas Storage. In Proceedings of the 2020 IEEE Power \& Energy Society Innovative Smart Grid Technologies Conference (ISGT), Washington, DC, USA, 17-20 February 2020; pp. 1-5.

49. Li, Y.; Zhang, F.; Li, Y.; Wang, Y. An improved two-stage robust optimization model for CCHP-P2G microgrid system considering multi-energy operation under wind power outputs uncertainties. Energy 2021, 223, 120048. [CrossRef]

50. Lehner, M.; Tichler, R.; Steinmüller, H.; Koppe, M. Power-to-Gas: Technology and Business Models; Springer: Berlin/Heidelberg, Germany, 2014.

51. Zhang, X.; Bauer, C.; Mutel, C.L.; Volkart, K. Life Cycle Assessment of Power-to-Gas: Approaches, system variations and their environmental implications. Appl. Energy 2017, 190, 326-338. [CrossRef]

52. Nastasi, B.; Mazzoni, S.; Groppi, D.; Romagnoli, A.; Garcia, D.A. Solar power-to-gas application to an island energy system. Renew. Energy 2021, 164, 1005-1016. [CrossRef]

53. Jentsch, M.; Trost, T.; Sterner, M. Optimal use of power-to-gas energy storage systems in an $85 \%$ renewable energy scenario. Energy Procedia 2014, 46, 254-261. [CrossRef]

54. Lekvan, A.A.; Habibifar, R.; Moradi, M.; Khoshjahan, M.; Nojavan, S.; Jermsittiparsert, K. Robust optimization of renewable-based multi-energy micro-grid integrated with flexible energy conversion and storage devices. Sustain. Cities Soc. 2020, 64, 102532. [CrossRef]

55. Esfandi, S.; Baloochzadeh, S.; Asayesh, M.; Ehyaei, M.A.; Ahmadi, A.; Rabanian, A.A.; Das, B.; Costa, V.A.; Davarpanah, A. Energy, Exergy, Economic, and Exergoenvironmental Analyses of a Novel Hybrid System to Produce Electricity, Cooling, and Syngas. Energies 2020, 13, 6453. [CrossRef]

56. Hemmati, M.; Mohammadi-Ivatloo, B.; Ghasemzadeh, S.; Reihani, E. Risk-based optimal scheduling of reconfigurable smart renewable energy based microgrids. Int. J. Electr. Power Energy Syst. 2018, 101, 415-428. [CrossRef]

57. Amir, V.; Azimian, M. Dynamic multi-carrier microgrid deployment under uncertainty. Appl. Energy 2020, 260, 114293. [CrossRef]

58. Hemmati, M.; Abapour, M.; Mohammadi-Ivatloo, B. Optimal scheduling of smart Microgrid in presence of battery swapping station of electrical vehicles. In Electric Vehicles in Energy Systems; Springer: Berlin/Heidelberg, Germany, 2020; pp. $249-267$.

59. Kaviani, R.; Rashidinejad, M.; Abdollahi, A. A milp igdt-based self-scheduling model for participating in electricity markets. In Proceedings of the 2016 24th Iranian Conference on Electrical Engineering (ICEE), Shiraz, Iran, 10-12 May 2016 ; pp. 152-157.

60. Nezhadnaeini, M.F.; Hajivand, M.; Abasi, M.; Mohajeryami, S. Optimal allocation of distributed generation units based on two different objectives by a novel version group search optimizer algorithm in unbalanced loads system. Rev. Roum. Des Sci. Tech. 2016, 61, 338-342.

61. Jannati, J.; Nazarpour, D. Optimal performance of electric vehicles parking lot considering environmental issue. J. Clean. Prod. 2019, 206, 1073-1088. [CrossRef]

62. Li, Y.; Liu, W.; Shahidehpour, M.; Wen, F.; Wang, K.; Huang, Y. Optimal operation strategy for integrated natural gas generating unit and power-to-gas conversion facilities. IEEE Trans. Sustain. Energy 2018, 9, 1870-1879. [CrossRef]

63. Hemmati, M.; Ghasemzadeh, S.; Mohammadi-Ivatloo, B. Optimal scheduling of smart reconfigurable neighbour micro-grids. IET Gener. Transm. Distrib. 2018, 13, 380-389. [CrossRef]

64. Hemmati, M.; Mohammadi-Ivatloo, B.; Soroudi, A. Uncertainty management in decision-making in power system operation. In Decision Making Applications in Modern Power Systems; Elsevier: Amsterdam, The Netherlands, 2020; pp. 41-62.

65. Golmohamadi, H.; Keypour, R. Stochastic optimization for retailers with distributed wind generation considering demand response. J. Mod. Power Syst. Clean Energy 2018, 6, 733-748. [CrossRef]

66. Golmohamadi, H. Operational scheduling of responsive prosumer farms for day-ahead peak shaving by agricultural demand response aggregators. Int. J. Energy Res. 2021, 45, 938-960. [CrossRef] 